\title{
To Cultivate Neourethra of Autologous for Proximal Hypospadias Repair of No Associated with Severe Chordee
}

\author{
Liu Guoqing*, Liu Shihui , Zhang Shilin, Wang Jianfeng, Li Jierong and Li Chunjing \\ Department of Surgery, Foshan Maternal and Child Health Care Hospital Affiliated to Southern Medical University, China
}

Received: June 18, 2018; Published: July 03, 2018

*Corresponding author: Liu Guoqing, Department of Surgery, Foshan Maternal and Child Health Care Hospital Affiliated to Southern Medical University, 528000, China

\begin{abstract}
Background: Hypospadias is a common congenital disease and the incidence of live birth is about 1/1250 1/1830 [1]. The most typical is ectopic urethra, the ventral curved downwards of penis, and dorsal skin is "hooded". According to the urethral open position, $80 \%$ of patients have a distal malpositioning of the meatus that requires a single-stage repair and nearly $20 \%$ have a more severe proximal meatus malposition, which may require two to three stage repair operations. The more serious the initial problem, the higher the complication rate, and the more operations the patient is likely to require. The common postoperative complications of hypospadias include urethrocutaneous fistula, urethral stricture (dysuria) and ventral penile curvature. In a large number of reports of surgical treatment of hypospadias, the evaluation indicators are all complications that are easy to find in the early stages. The performance and acceptability are based on short-term observations. As for satisfaction, it is not possible to seek the opinions of the patients. The final assessment of the effect of the operation can only be determined based on their parents' "degree of satisfaction". In view of the incomplete evaluation index of existing treatment effects, many authors proposed the appearance of the penis, penile curvature and urination function as a new index of hypospadias surgery. Research suggests that the preoperative assessment of the severity of hypospadias and the rational choice of surgical methods are important guarantees for the reduction of postoperative complications of hypospadias, and also for the satisfaction of the appearance of the penis and normal sexual function.
\end{abstract}

Surgical operation is the only way to treat hypospadias, but, due to the great reasons, occurrence rates of complications such as the urethral fistula or constriction, reoccurrence of clubbed penis, poor development of penis and poor appearance of penis are still quite high after operation, indicating that the therapeutic effect of operation have relativities with selected the cure technique.

Purpose: To describe a new technique which to Cultivate Neourethra of Autologous(CUA) for proximal hypospadias repair.

\section{Material and Methods}

Clinical Material: A total of 287 patients with hypospadias ranged in age from 1 month to 7 years (average 10.5 months), of which 164 patients in the cured group and 123 patients in the control group had proximal hypospadias.

Operation Methods: To utilize the urethra plate to reconstruct a neourethral, longitudinal incision of the septum of scrotum and dartos muscle of scrotum, imbedding the ventral prepuce and corpus spongiosum together with the neourethral and dartos muscle of scrotum, stratified the dartos muscle of scrotum and the skin of septum of scrotum and ventral prepuce corresponding suture, the neourethral was cultivated with a good blood supply of the dartos muscle of scrotum. After 6 months, the second-stage surgery will be performed Meatoplasty and Glanuloplastyto correct abnormal ventral curvature of the penis.

Results: The CUA technique was used in 164 patients in the treatment group, 4 of them (2.4\%) had urethral fistulas, $1(0.6 \%)$ had urethral strictures, and 5 (3.05\%) had recurrent epiphyseal epithelium. Among the 123 patients in the control group, 7 (5.7\%) had urethral fistula, 5 $(4.1 \%)$ had urethral stricture, and $3(2.4 \%)$ had recurrence of penile condyle. The incidence of surgical complications in the two groups was $6.1 \%$ and $12.2 \%$, respectively $(\mathrm{p}<0.01)$.

Conclusion: The CUA technique is a reliable technique for proximal hypospadias repair. It has particular value that abundant blood supply to tissue of the new construction urethra, pledge the neourethral continue growth, shortened time of operation and reduced capacity of bleed, effectively reduce the incidence rate of operation complication for hypospadias repair, adapt to most patients of proximal hypospadias operation repair.

Keywords: Autologous; Chordee; Curvature; Cultivate; Hypospadias; Neourethra; Proximal; Urethraplate

Abbreviations: CUA: Cultivate Neourethra Of Autologous; TIP: Tubularized Incised Plate Plasty; OIF: Onlay Island Flap

\section{Introduction}

According to the reports [1], the incidence of congenital hypospadias of male newborn is $1 / 1250 \sim 1 / 1830$. Surgical

operation is the only method of treatment of hypospadias, but because of great reasons, occurrence rates of complications such as 
the urethral fistula or constriction, reoccurrence of penile curvature, penile dysplasia and poor cosmetic appearance of penis are still quite high after operation [2], indicating that the therapeutic effect of operation is related to selected the chosen healing technique. Studies have found that the urethral plate tissues have abundant of blood vessels, nerves, glands, smooth muscle and connective tissue, no hair follicle structure, no defects such as sebum secretion or hair grow, and consistent with the corpus spongiosum, conform to the anatomical and physiological requirements of the natural urethra. Clinical and animal studies have shown that in the dorsal incision of the urethral plate epidermis cells and vascular develop normally, proliferation of epithelial cells, cover with epithelial cells, and the formation of new epithelium, and a small amount of fibroblasts can be observed. Consider urethra plate is the best selftissue of urethroplasty. This report from January 2007 to December 2015, we are performed the Cultivate Urethra of Autologous(CUA) technique for hypospadias repair, and follow-up the patients.

\section{Clinical Information}

A total 287 patients underwent surgery at the Foshan Maternal and Child Health Care Hospital Affiliated to Southern Medical University, from January 2007 to December 2015, age 1 month to 7 years (mean 10.5 months). A total 164 cases of cure group, of which 84 cases are penis-scrotum, 52 cases of scrotum type, and 28 cases of perineum type; while in the control group with 123 cases, 69 cases of penis scrotum, 37 cases of scrotum, and 17 cases of perineum type. The ethical committee of Foshan Maternal and Child Health Care Hospital Affiliated to Southern Medical University has approved and fill in the informed consent form (Table 1).

Table 1: Baseline.

\begin{tabular}{|c|c|c|c|}
\hline & CUA164 case & $\begin{array}{c}\text { Control Group } \\
\text { of 123 Cases }\end{array}$ & P \\
\hline $\begin{array}{c}\text { Age (year, mean } \\
\pm \text { SD) }\end{array}$ & $9.8 \pm 4.4$ & $10.6 \pm 3.7$ & 0.47 \\
\hline $\begin{array}{c}\text { PH type (n, \%) } \\
\text { Penis-scrotum } \\
\text { Type }\end{array}$ & $84,51.2$ & $69,56.1$ & \multirow{2}{*}{} \\
\cline { 2 - 3 } & $52,31.7$ & $37,30.1$ & \\
\hline Scrotum Type & $28,17.1$ & $17,13.8$ & \multirow{2}{*}{0.43} \\
\hline Perineum Type & $121,73.8$ & $87,70.7$ & \\
\hline Chordee (n, \%) & $85,51.8$ & $56,45.5$ & \\
\hline $\begin{array}{c}\text { Other findings } \\
\text { (n, \%) }\end{array}$ & $101,61.6$ & $71,57.7$ & \\
\hline $\begin{array}{c}\text { Penoscrotal } \\
\text { transposition }\end{array}$ & $17,10.4$ & $13,10.6$ & \\
\hline Bifid scrotum & & \\
\hline $\begin{array}{c}\text { Undescended } \\
\text { testis }\end{array}$ & & & \\
\hline
\end{tabular}

\section{Inclusion and Exclusion Criteria:}

a. Inclusion: Not associated with severe chordee of the penis with the penis-scrotum type, scrotum type and perineum type of hypospadias.

b. Exclusion: If the penis abnormalities angle greater than 30 degrees of the hypospadias.(Editor-in-chief, Alan J. Wein; editors, Louis R. Kavoussi et al:Campbell-Walsh Urology, 10th ed. Philadelphia: W.B. Saunders, 2012.3486-3452.).
Patients were divided into CUA group and Control group according to the treatments. Both groups of patients are the same surgeon and chief physician. Surgeons are the attending physicians or above, and can perform surgery skillfully.

\section{A. CUA Group}

All 164 cases of cure group underwent the Cultivate Urethra of Autologous(CUA) technique (Figure1-6):

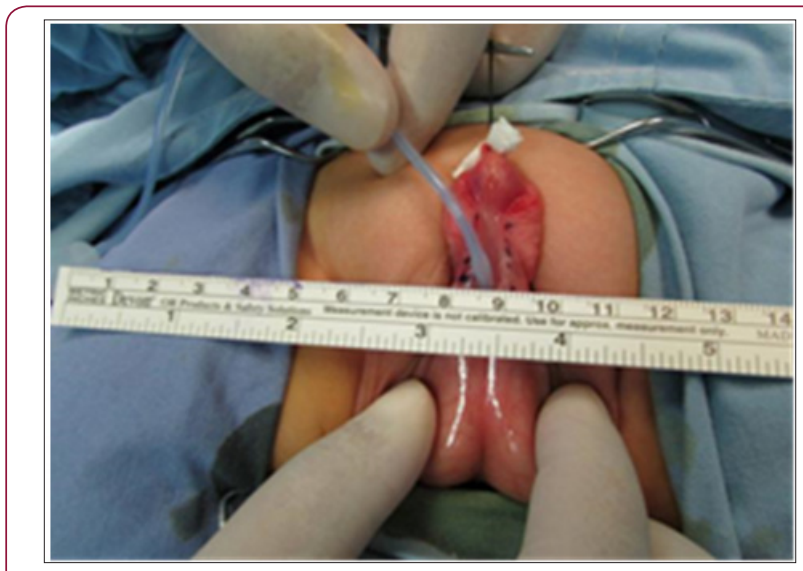

Figure 1: Synthetic evaluated before operation.

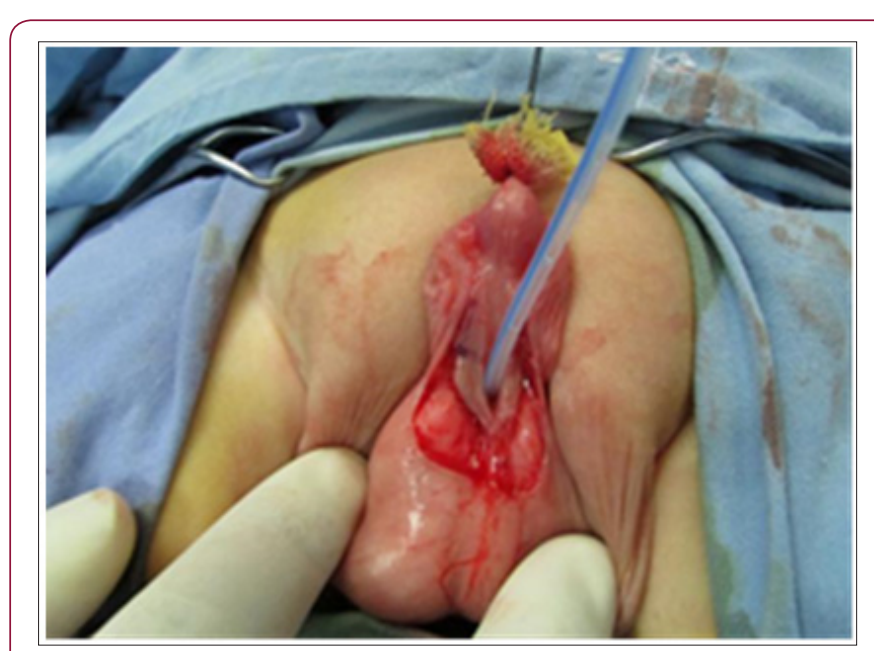

Figure 2: U-shaped incision the urethral plate.

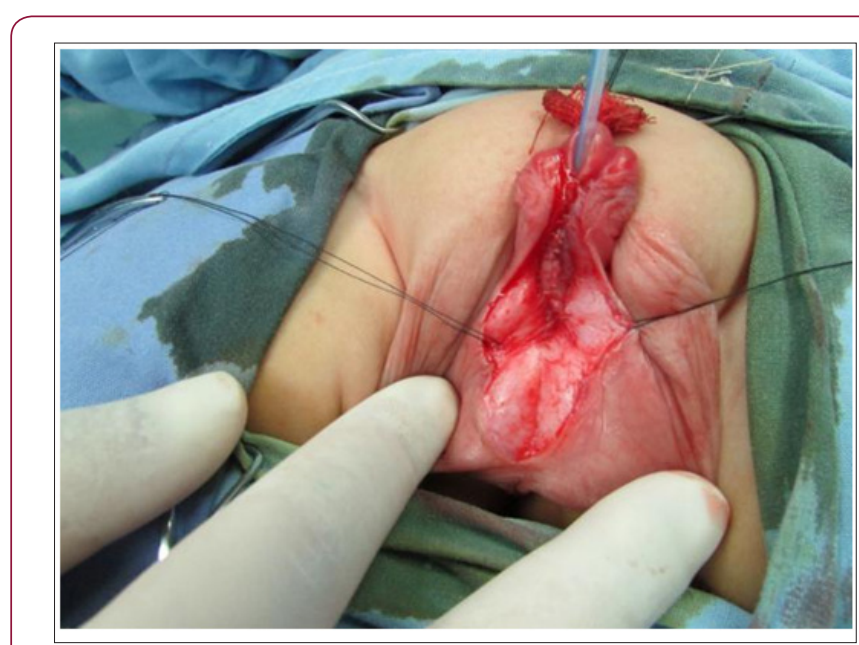

Figure 3: Reconstructed the urethral by sutured. 


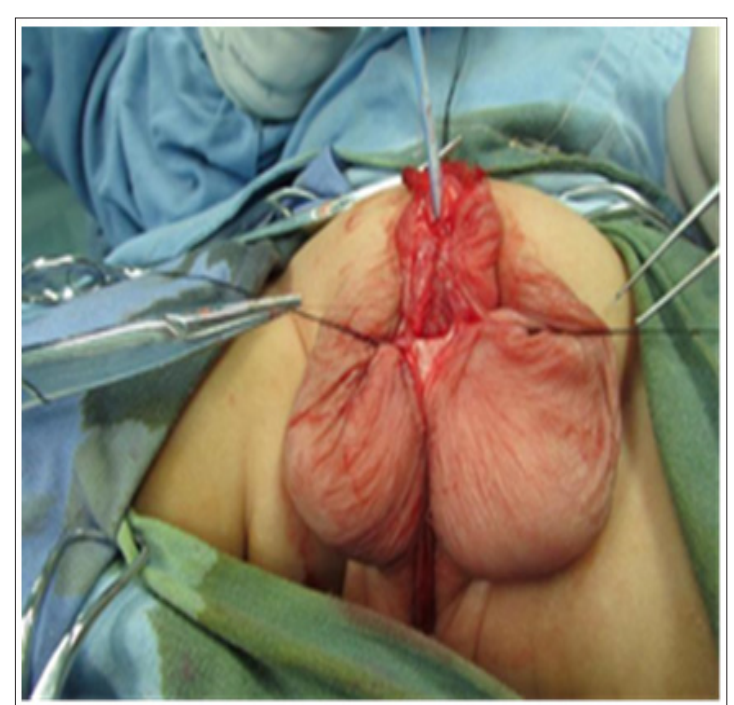

Figure 4: Take plated the neourethra in scrotum.

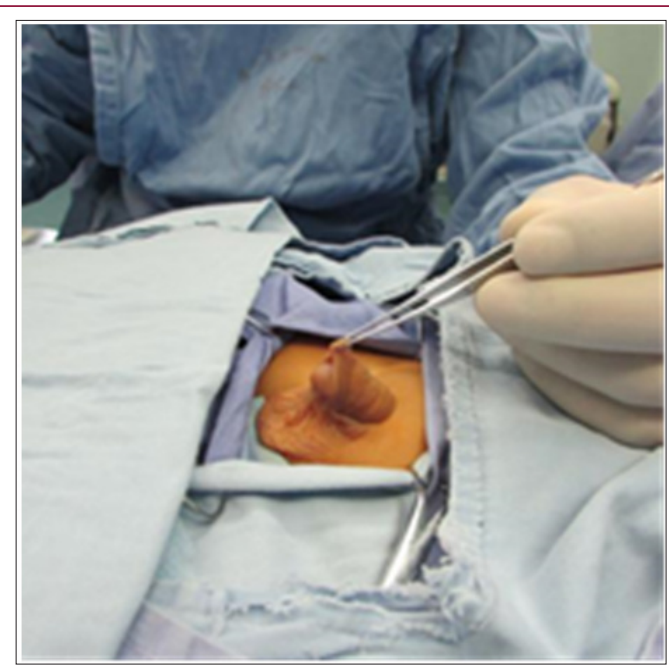

Figure 5: After 6 months, the appearance of penis

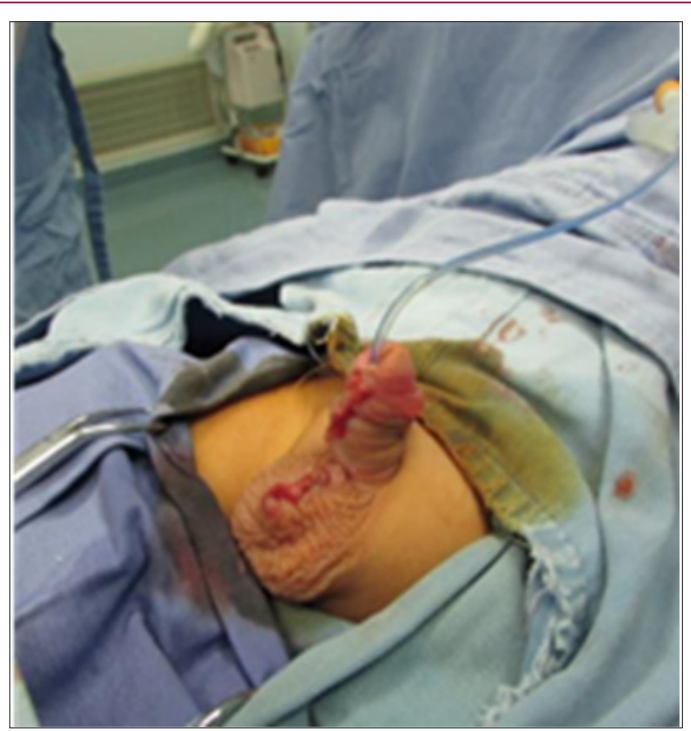

Figure 6: The appearance of penis after operation with Erected the chorde of penis.

\section{Stage I}

a. Comprehensive evaluation of preoperative hypospadias in each patient (Figure 1).

b. A U-shaped incision was made around the urethral plate border and hypospadias orifice (Figure 2).

c. The urethral plate strips are approximated ventrally to reconstruct a neourethra by using subcuticular $6 / 0$ polyglactin sutures in an interrupted manner (Figure 3).

d. Incision the medium of scrotum and take plated the neourethra with sarcolamma of scrotum. Retention a suitable sized stent of multihole (6 8Fr) was inserted into the bladder for urinate off.

\section{Stage II}

a. 6 months after the operation, a second operation was performed (Figure 5).

b. Free the neourethral with sarcolamma and scrotum, Chordee was identified by artificial erection (injection of $0.9 \%$ saline into the corpora of the penis). Reconstructed the skin of penis (Figure 6).

B. Control Group: The control group 123 cases, 51 cases of the TabularizedIncised Plate Plasty(TIP), 29 cases of Mathieu plasty, 30 cases of Onlay Plasty(onlay island flap, OIF) and 13 cases of Koyanagiplasty. Control group received surgery method including:

1) Tubularized Incised Plate Plasty(TIP): TubularizedIncised Plate (TIP) technique is described for correction of distal hypospadias with minimal chordee. The key step is deep longitudinal incision of the plate, which allows for tubularization without the need for additional flaps.

2) Mathieu Plasty: In Mathieu's repair, the urethral plate and perimeatal-based flap were marked. Typically, the width of $7.5 \mathrm{~mm}$ was measured for the proximal flap. Longitudinal lines outlining the urethral plate were then drawn extending along the length of required flap. Urethral plate and proximal shaft skin were incised about 7-8mm wide and the penis was degloved after subcoronal circumferential incision. Granular wings were developed by deep dissection under glans to perform tension free glanuloplasty. Proximal shaft skin flap was mobilized and transposed toward the urethral plate. This flap was folded over the urethral meatus and neourethra formed over 6 or 8 Fr tube wit interrupted 6-0 polygalactin knots outside. Glanuloplasty and skin coverage completed the procedure. The key modification is the design of a converging incision and the technique of suturing.

3) Onlayplasty (Onlay Island Flap, OIF): The principles of onlay island flap urethroplasty are: mobilizing of urethral plate, without dividing it, in order to release chordee; creation of pedicle island flap on the dorsal penile skin, with redundant vascularized tissue, which is transposed to the ventral side of penis by buttonhole maneuver; the flap is onlayed to the 
mobilized urethral plate, while all suture lines are covered with a very wide pedicle of flap, which is decisive for the successful outcome of the operation.

4) Koyanagi's Plasty: The operative technique consists of 7 steps, including

i. Outlining the skin incision and dartos mobilization;

ii. Artificial erection, harvesting parameatal foreskin flap and release of chordee as needed;

iii. Glans splitting and creation of glanular wings;

iv. 1-Stage urethroplasty with parameatal foreskin flap;

v. Meatalglanuloplasty;

vi. Creation of Byars' flaps of the skin, and

vii. Skin Closure. Central to the technique is the feasibility of the choice of 1-stage urethroplasty with meatal based manta-wing flap or with parameatal based and fully extended circumferential foreskin flap even after the skin incision is made, which enables its application to all types of hypospadias.

C. Postoperative complications: Follow-up period ranged from 18 months to 7 years (mean, 32 months). Includes: urethrocutaneous fistula, urethral stricture, recurrence of penile curvature, and the penis cosmetic appearance and so on.

a. Urethrocutaneous Fistula: Refers to the urethral reconstruction using abnormal passage between the skin of the penis, urine leakage when urinating overflow.

b. Urethral Stricture: Refers to the urethral reconstruction using thinner scar hyperplasia caused by urethral, clinical manifestations are dysuria.

c. Recurrence of the Penile Curvature: After hypospadias surgical with corrective of penile curvature causes recurrence of the penile curvature.

d. Defects of the Penis Cosmetic: The patients and them parents are not satisfied with the appearance of the penis on Postoperative.

\section{Results}

The control group included 123 cases(distal 49, proximal 74) selected the TubularizedIncised Plate Plasty(TIP) 51 cases, Mathieu plasty 29 cases, OnlayPlasty(onlay island flap, OIF) 30 cases and Koyanagiplasty 13 cases. 164 cases performed CUA technique in cure group, the operation time of the first stage is 35 45 minutes, bleed about $3 \sim 5 \mathrm{ml}$, the second stage time is 65 98 minutes, bleed about $5 \sim 15 \mathrm{ml}$, two-periods total operation time average was 112.8 minutes, average bleed about $12.5 \mathrm{ml}$, among 4 cases $(2.4 \%)$ developed urethral fistula, 1 cases $(0.6 \%)$ urethral constriction, 5 cases $(3.5 \%)$ reoccurrence of clubbed penis. The control group of 123 cases, total operation time average was 145.6 minutes, total bleed about $23.3 \mathrm{ml}$, urethral fistula 7 cases $(5.7 \%)$, urethral stricture 5 cases $(4.1 \%), 3$ cases $(2.4 \%)$ reoccurrence of clubbed penis. Two groups of total operation time and total bleed has significant difference $(\mathrm{p}<0.01)$, the rate of operation complication of is $6.1 \%$ and $12.2 \%$ respectively $(\mathrm{p}<0.01)$ (Table 2 ).

Table 2: Postoperative complications.

\begin{tabular}{|c|c|c|c|}
\hline & CUA Group & Control Group & $\mathbf{P}$ \\
\hline & $n=164$ & $n=123$ & \\
\hline Total (n, \%) & $10,6.1 \%$ & $15,12.2 \%$ & $<0.01$ \\
\hline Urethral Fistula & $4,2.4 \%$ & $7,5.7 \%$ & \\
\hline $\begin{array}{l}\text { Recurrent } \\
\text { Curvature }\end{array}$ & $5,3.0 \%$ & $3,2.4 \%$ & \\
\hline $\begin{array}{c}\text { Urethral } \\
\text { Constriction }\end{array}$ & $1,0.6 \%$ & $5,4.1 \%$ & \\
\hline $\begin{array}{l}\text { operation time } \\
\text { (minute, mean } \\
\pm \mathrm{SD} \text { ) }\end{array}$ & 112.8 & 145.6 & $<0.01$ \\
\hline First Stage & $35-45$ & & \\
\hline Second Stage & $65-98$ & & \\
\hline $\begin{array}{c}\text { Bleed (ml, mean } \\
\pm \mathrm{SD})\end{array}$ & 12.5 & 23.3 & $<0.01$ \\
\hline First Stage & $3-5$ & & \\
\hline Second Stage & $5-15$ & & \\
\hline
\end{tabular}

\section{Discussion}

The operation for hypospadias repair is still continuous improvement and evolution [2]. At present, the cure standard of hypospadias is not only satisfying sex life quality and standing micturition, satisfying cosmetic appearance is also very important. The general research thinks [3],a kind of excellent kill for hypospadias repair should be advantageous to protect supply blood of the distal skin flap, guarantees healing and growth of the neourethra, effectively reduces of the operation times and the rate of operation complication, increase the surgical cure rate [4], as well as achieves satisfaction of the function and cosmetic appearance of the penis [5]. Due to the recognition of urethral plate tissue [6], the urethroplasty of using urethral plate has become a common surgical method for hypospadias repair, the TIP surgery method(Tubularized incised plate plasty) is very good at protecting the anatomical and physiological functions of the urethral. Take the operation treatment for hypospadias repair becomes more easier and effective, therefore, this method has become one of the most important operation methods in the treatment of hypospadias. It is considered that [7] the TIP operation is simple, less bleeding, shorter operation time and quicker recovery after operation, which is suitable for the correction and repair of most hypospadias.

The research showed that [8] the wound of mucosal tissue in the dorsal incision of the urethral plate can be completely repaired after 7 10 day, without any scar tissue, the new epidermal tissue and blood vessels can fully the development needs of the neourethra, which is suitable for the surgical repair of various hypospadias, suggesting that urethral plate tissue is one of the best self-tissue for repairing hypospadias. However, the disadvantage of TIP method is that [9] the high of incidence of operation complications such as urethral cutaneous fistula, urethral stricture 
and the recurrence of penile ventral curvature, which is related to the urethral plate of dysplasia, poor blood supply and weak tissue regeneration. Mathieu, Onlay, Koyanagi and other surgical methods [10], because keep the partial or completely reserved the urethral plate, the use of the prepuce and urethral plate tissues with combined flaps repair of hypospadias, have a certain advantages of the keep urethral plate operation for hypospadias repair, that is good clinical treatment effect, better cosmetic appearance of the penis, Satisfactory physiological function. However [11], because of this kind of operation method, did not solve urethral plate and skin tissue flap dysplasia, blood supply insufficiency, the tissue distributes unreasonable and so on, although to a certain extent solves question of the penile curvature recurrence, but the high complication rate of the postoperative as the urethra fistula, urethral stricture, is the main problem of leads to the failure in the operation.

In recent years [12], with the continuous accumulation of clinical experience, with the new technology and the materials of wide use, new operating skills of innovation and development, Mathieu, Onlay, Koyanagi and other methods of some of the shortcomings have been better resolved [13], so that the healing rate of hypospadias repair gradually increased, Therefore, it has aroused widespread concern. The authors found that [14] the surgical cure rate of the operation for hypospadias repair of using the urethral plate urethroplasty was closely related of the anatomical and histological features of urethral plate tissue, and reasonable choice of hypospadias surgery method. The Before of the surgery [15], the operative doctors take of classifying, grouping and grading by the urethral plate tissue morphology and histological characteristics, choosing appropriate operation method, with the abundant blood supply of scrotal dartos fascia to cultivating neourethra, can effectively avoid the defects of urethral plate tissue dysplasia, insufficiency of blood supply and weak tissue regeneration, to improve the surgical cure rate of hypospadias repair. Scrotal tissue [16] is the itself, with abundant blood supply and anti-infection ability, and adjacent to urethra, can effectively protect the blood supply of neourethra, promote tissue cell regeneration, promote the healing and growth of the neourethra, effectively reduce urethral fistula, urethral stricture and other operation complications, improve the success rate of hypospadias surgery, Is the ideal tissue culture medium for the development of neourethra.

Therefore, based on the above research, we have designed a new surgical method, namely the Cultivate Urethra of Autologous (CUA), the operative method is, using urethra plate reconstruction of the neourethra, longitudinal incision the skin and dartos fascia of scrotum, take the penis with neourethra to the combined embedding in the scrotal dartos fascia, stratified suture the skin and dartos of scrotum and penis, the neourethra use scrotal good blood supply to cultivate. After 6 months, second stage surgery will be performed to correct penile curvature and penile plasty. In the study, 164 patients were treated with CUA in the treatment group. The duration of the first-stage operation lasted 35 to 45 minutes, and the bleeding volume was 3 to $5 \mathrm{ml}$. The second-stage operation lasted for 65 to 98 minutes, and the bleeding volume was 5 to $15 \mathrm{ml}$. The average operation time was 112.8 minutes. The average amount of blood loss was about 12.5 milliliters, including 4 cases $(2.4 \%)$ of urethral fistula, 1 case $(0.6 \%)$ of urethral contracture, and 5 cases(3.1\%) of reoccurrence of penile curvature. There were 123 patients in the control group. The total operation time was 145.6 minutes on average. The total bleeding was about $23.3 \mathrm{ml}$. There were 7 cases $(5.7 \%)$ of urethral fistula, 5 cases(4.1\%) of urethral stricture, and 3 cases (2.4\%) of reoccurrence of penile curvature. There was a significant difference $(\mathrm{p}<0.01)$ in the total operation time and total bleeding. The incidence of surgical complications was $6.1 \%$ and $12.2 \%$, respectively $(\mathrm{p}<0.01)$.

It is indicated that this surgical method of the Cultivate Urethra of Autologous (CUA) technique is good, it has particular value that abundant blood supply to the tissue to construct neourethra, pledged the neourethra continue growth, shortened time of operation and reduced capacity of bleed, effectively reduced the incidence rate of operation complication for hypospadias repair, adapted to most patients of proximal hypospadias operation repair.

However, we should give sufficient attention to the limitation of the correction [17], as for proximal hypospadias with severe chordee of penis, the feasibility of this technique needs to be observed further. Furthermore, that vascularity of penile tissues decreases with successive operations, and it should be considered [18] the techniques and measures of how to ensure the vascular supply of flap tissue.

\section{References}

1. Springer A, van den Heijkant M, Baumann S (2016) Worldwide prevalence of hypospadias. J Pediatr Urol 12(3): 152.e1-7.

2. Arlen AM, Kirsch AJ, Leong T (2015) Further analysis of the GlansUrethral Meatus-Shaft (GMS) hypospadias score: correlation with postoperative complications. J Pediatr Urol 11(2): 71.e1-5.

3. Elmoghazy H, Hussein MM, Mohamed E, Badawy A, Alsagheer G, et al. (2016) A novel technique for repair of mid-penile hypospadias using a preputial skin flap: results of 110 patients. Int Urol Nephrol 48(12): 1943-1949.

4. Thiry S, Saussez T, Dormeus S, Tombal B, Wese FX, et al. (2015) LongTerm Functional, Cosmetic and Sexual Outcomes of Hypospadias Correction Performed in Childhood. Urol Int 95(2): 137-141.

5. Liu MM, Holland AJ, Cass DT (2015) Assessment of postoperative outcomes of hypospadias repair with validated questionnaires. J Pediatr Surg 50(12): 2071-2074.

6. Akbiyik F, TiryakiT ,Senel E, Mambet E, Livanelioglu Z, et al. (2009) Clinical experience in hypospadias: results of tubularized incised plate in 496 patients. Urology 73(6): 1255-1257.

7. Al Ghorairt BA, Elashry OM, Al Housain AE, Mattar AA (2009) Analysis of five-year experience with tubularized incised plate urethroplasty for anterior and mid penile hypospadias. Eur J Pediatr surg 19(2): 90-95.

8. Snodgrass WT, Patterson K, Plaire JC, Grady R, Mitchell ME ( 2000) Histology of the urethral plate: implications for hypospadias repair. J Urol 164(3 Pt 2): 989-990.

9. DE Mattos e Silva E, Gorduza DB, Catti M, Valmalle AF, Demède $D$, et al. (2009) Outcome of severe hypospadias repair using three different techniques. J Pediatr Urol 5(3): 205-211.

10.González R, Lingnau A, Ludwikowski BM (2018) Results of Only Preputial Flap Urethroplasty for the Single-Stage Repair of Mid- and Proximal Hypospadias. Front Pediatr 6:19.

11. Moursy EE (2009) Outcome of proximal hypospadias repair using three different techniques. JPediatr Urol Jun 8. 
12. Jayanthi VR (2008) The modified Koyanagi hypospadias repair for the one-stage repair of proximal hypospadias. Indian J Urol 24(2): 206-209.

13. Van der Horst HJ, De Wall LL (2017) Hypospadias, all there is to know. Eur J Pediatr 176(4): 435-441.

14. Liu Guoqing, Zhang Shilin, WangJian feng, (2017) The Significance of age development characteristics of Urethral plate in surgical repair for Hypospadias. JJ Nephro Urol 4(1): 32.

15. Erol A, Baskin LS, Li YW, Liu WH (2000) Anatomical studies of the urethral plate: why preservation of the urethral plate is important in hypospadias repair. BJU Int 85(6):728-734.

(c) (P) This work is licensed under Creative

Submission Link: https://biomedres.us/submit-manuscript.php
16. Liu Guoqing (2013) The clinical significance of comprehensive classification of the hypospadias with surgical treatment in fants. Zhonhua Nan Ke Xue (9): 849-852.

17. Liu GQ Tang HJ, Zhao YW, Wang JF, Li H, et al. (2006) One stage repairing operation in neonatal hypospadias. Zhonhua Nan Ke Xue 12(1): 66-67.

18. Snodgrass W, Bush NC (2017) Re-operative urethroplasty after failed hypospadias repair: how prior surgery impacts risk for additional complications. J Pediatr Urol 13(3): 289.

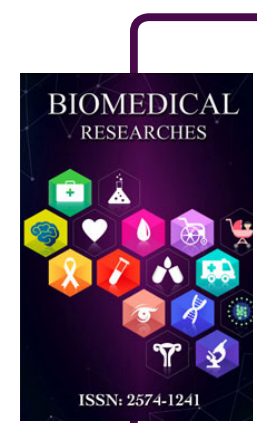

Assets of Publishing with us

- Global archiving of articles

- Immediate, unrestricted online access

- Rigorous Peer Review Process

- Authors Retain Copyrights

- Unique DOI for all articles

https://biomedres.us/ 